\title{
Feedback Linearization and Sliding Mode Control for VIENNA Rectifier Based on Differential Geometry Theory
}

\author{
Xiang Lu, ${ }^{1,2}$ Yunxiang Xie, ${ }^{1}$ and Li Chen ${ }^{1}$ \\ ${ }^{1}$ School of Electric Power, South China University of Technology, Guangzhou 510641, China \\ ${ }^{2}$ College of Physical Science and Technology, Guangxi University, Nanning 530004, China \\ Correspondence should be addressed to Xiang Lu; luxiang@gxu.edu.cn
}

Received 6 June 2014; Revised 28 August 2014; Accepted 4 September 2014

Academic Editor: Kang Li

Copyright (c) 2015 Xiang Lu et al. This is an open access article distributed under the Creative Commons Attribution License, which permits unrestricted use, distribution, and reproduction in any medium, provided the original work is properly cited.

\begin{abstract}
Aiming at the nonlinear characteristics of VIENNA rectifier and using differential geometry theory, a dual closed-loop control strategy is proposed, that is, outer voltage loop using sliding mode control strategy and inner current loop using feedback linearization control strategy. On the basis of establishing the nonlinear mathematical model of VIENNA rectifier in $d$ - $q$ synchronous rotating coordinate system, an affine nonlinear model of VIENNA rectifier is established. The theory of feedback linearization is utilized to linearize the inner current loop so as to realize the $d$ - $q$ axis variable decoupling. The control law of outer voltage loop is deduced by utilizing sliding mode control and index reaching law. In order to verify the feasibility of the proposed control strategy, simulation model is built in simulation platform of Matlab/Simulink. Simulation results verify the validity of the proposed control strategy, and the controller has a strong robustness in the case of parameter variations or load disturbances.
\end{abstract}

\section{Introduction}

With the development of power electronic technology, threelevel pulse width modulation (PWM) rectifiers are widely used in high or medium power converters because of their excellent performance: low switch voltage stress, low input current harmonic distortion, high efficiency, input power factor is unit, and so on [1-7]. Three-phase/switch/level VIENNA rectifier (abbreviated as VIENNA rectifier) is one of the best three-level rectifier, which is proposed in 1994 by Kolar and Zach. Compared with traditional three-level rectifier, such as diode clamping three-level rectifier, VIENNA rectifier has lots advantages, such as small number of power switch tube, simple control circuit, and low design costs, without output voltage bridge arm shoot-through problems. So, more and more scholars and engineers focus their attention on the study of VIENNA rectifier and its control strategy [3-14].

Since VIENNA rectifier is a typical strong coupling nonlinear system, it leads to difficulty in designing the controller. In $[8,9]$, the mathematical models of large and small signals topology are analyzed in detail, and the controller is designed by using proportion and integral (PI) algorithm. A control method of input/output accurate linearization is proposed in [10]. State-space average model is established, and PI control algorithm is used in the outer voltage loop; hysteresis control is used in the inner current loop in [11-13]. The control methods described above improved the performance of VIENNA rectifier to some extent. However, there are some disadvantages, such as system excessive dependence on the accurate mathematical model, inconvenience of parameter setting, complicated of control algorithm, and poor dynamic. In order to overcome the above drawbacks, this paper proposes a control strategy which combines feedback linearization control and sliding mode control.

In recent decades, nonlinear control theory has made great progress, especially feedback linearization theory based on differential geometry. In this method, nonlinear system can achieve status or input/output linearization by using a certain nonlinear state transformation or feedback transformation. Feedback linearization control has been applied to three-phase voltage PWM rectifier [14-16], which is a multivariable and strong coupling nonlinear system, and achieved well control effect. All these methods can solve 
the problem of decoupling for original nonlinear system and obviously improve static and dynamic performance for three phase rectifier. Yet, this control method depends on an accurate mathematical model and is sensitive to system parameters. Sliding mode control is different from feedback linearization control method. Sliding mode control shows great robustness and stays out of parameter changes when the system is running in the sliding surface. In [17-20], sliding mode control has been applied to the three-phase PWM rectifier and achieved a good result.

The three-phase PWM rectifier is a two-level rectifier, while the VIENNA rectifier is a three-level rectifier. Although their structure is not the same, there are some similarity in control strategy. Learning from the applications of feedback linearization control and sliding mode control for threephase PWM rectifier, this paper integrates feedback linearization control method and sliding mode control method and eventually establishes a new type of VIENNA rectifier nonlinear control system. That is, sliding mode control is used in the outer voltage loop and state feedback linearization control is used in the inner current loop. At the same time, space vector pulse width modulation (SVPWM) technology is introduced to modulate the output signal of inner currentloop [21]. In order to reduce the chattering phenomenon produced by sliding mode control, index reaching law is adopted to improve the whole approaching process. In order to verify the correctness and superiority of the proposed control strategy, numerical simulation is done.

\section{Physical and Modeling Considerations}

In this section, the physical system and the mathematical model of VIENNA rectifier are presented. The main circuit of VIENNA rectifier and its simplified model are shown in Figures 1(a) and 1(b), respectively. The main circuit includes six fast-recovery diodes $\left(D_{1}-D_{6}\right)$, three boost inductors, three bidirection power switching tubes $\left(S_{a}, S_{b}\right.$, and $S_{c}$ as shown in the dashed box), and two groups of output capacitances. Among them, $e_{a}, e_{b}, e_{c}$ are the AC input power of VIENNA rectifier; $C_{1}$ and $C_{2}$ are DC side output voltage filter capacitor, and their voltage across, respectively, are $V_{\mathrm{C} 1}, V_{\mathrm{C} 2} ; R_{l}$ is load resistance and the voltage across is $V_{d c}$, and $i_{l}$ is the output current; $L$ is the boosting inductor and $R$ is defined as an equivalent resistance of inductor. In order to simplify the system, all the power-switching devices are seen as ideal and switching frequency is much higher than the grid frequency.

The mathematical model of VIENNA rectifier in $a b c$ coordinates can be expressed as follows:

$$
Z \frac{d X}{d t}=A X+B E
$$

where

$$
\begin{aligned}
Z & =\left[\begin{array}{lllll}
L & L & L & C_{1} & C_{2}
\end{array}\right], \\
X & =\left[\begin{array}{lllll}
i_{a} & i_{b} & i_{c} & V_{C 1} & V_{C 2}
\end{array}\right]^{T}, \\
B & =\left[\begin{array}{lllll}
1 & 1 & 1 & 0 & 0
\end{array}\right], \\
E & =\left[\begin{array}{lllll}
e_{a} & e_{b} & e_{c} & 0 & 0
\end{array}\right]^{T}, \\
A & =\left[\begin{array}{ccccc}
-R & 0 & 0 & -\left(S_{a p}-\frac{S_{a p}+S_{b p}+S_{c p}}{3}\right) & \left(S_{a n}-\frac{S_{a n}+S_{b n}+S_{c n}}{3}\right) \\
0 & 0 & -R & -\left(S_{c p}-\frac{S_{a p}+S_{b p}+S_{c p}}{3}\right) & \left(S_{c p}-\frac{S_{a p}+S_{b p}+S_{c p}}{3}\right) \\
S_{a p} & S_{b p} & S_{c p} & -\left(S_{b p}\right) \\
-S_{a n} & -S_{b n} & -S_{c p} & 0 & -\frac{1}{R_{l}}
\end{array}\right] .
\end{aligned}
$$

With Park's transformation, the mathematical model of VIENNA rectifier in $d-q$ coordinates system is given as follows:

$$
\begin{aligned}
& L \frac{d i_{d}}{d t}=-R i_{d}+\omega L i_{q}-S_{d p} V_{C 1}+S_{d n} V_{C 2}+e_{d}, \\
& L \frac{d i_{q}}{d t}=-\omega L i_{d}-R i_{q}-S_{q p} V_{C 1}+S_{q n} V_{C 2}+e_{q}
\end{aligned}
$$

$$
\begin{gathered}
C \frac{d V_{C 1}}{d t}=\frac{3}{2} S_{d p} i_{d}+\frac{3}{2} S_{q p} i_{q}-i_{l}, \\
C \frac{d V_{C 2}}{d t}=-\frac{3}{2} S_{d n} i_{d}-\frac{3}{2} S_{q n} i_{q}-i_{l},
\end{gathered}
$$

where $e_{d}$ and $e_{q}$ are the grid voltage variable in $d$-q coordinate system; $i_{d}$ and $i_{q}$ are the grid current variable in $d-q$ coordinate system. As for $S_{d p}, S_{d n}, S_{q p}$, and $S_{q n}$, they are the switching function in $d-q$ coordinate system for 


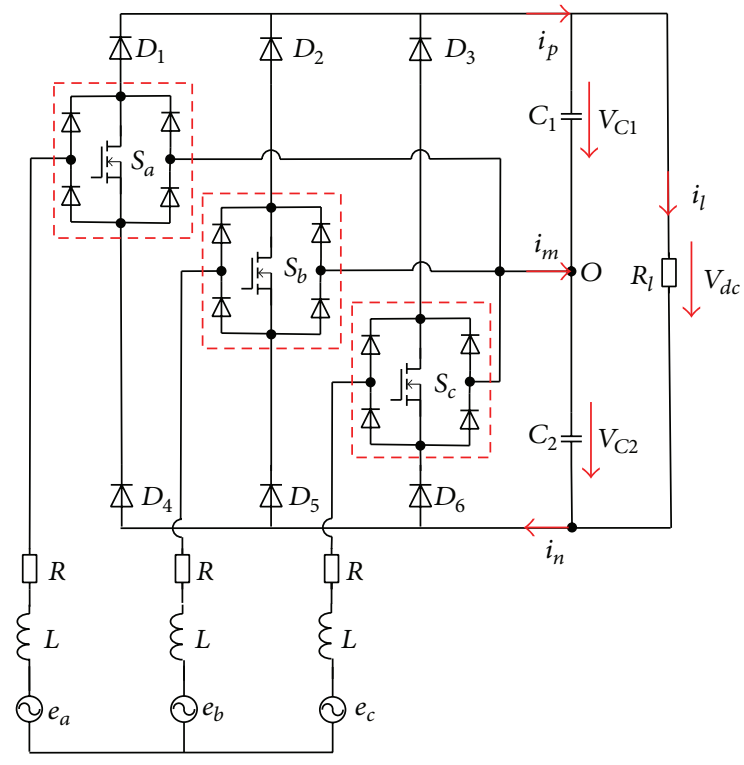

(a)

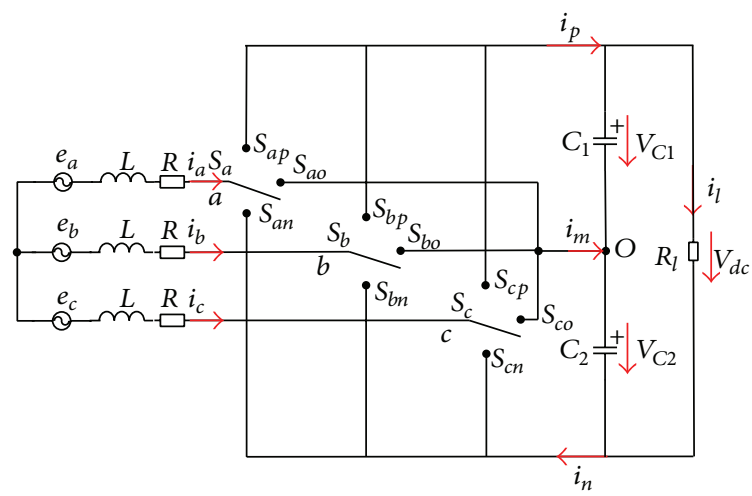

(b)

FIgURE 1: Main circuit of VIENNA rectifier and its simplified model.

$S_{x}(x=a, b, c)$. The equivalent circuit of VIENNA rectifier in $d$-q coordinate system is shown in Figure 2.

For three-phase balance power grid, because of $C_{1}=C_{2}=$ $C$, yield $V_{C 1}=V_{C 2}=(1 / 2) V_{d c}$. Assume that

$$
\begin{aligned}
& S_{d}=S_{d p}-S_{d n}, \\
& S_{q}=S_{q p}-S_{q n} .
\end{aligned}
$$

Thus, (3) and (4) can be rewriten as follows:

$$
\begin{aligned}
& L \frac{d i_{d}}{d t}=-R i_{d}+\omega L i_{q}-\frac{S_{d}}{2} V_{d c}+e_{d}, \\
& L \frac{d i_{q}}{d t}=-R i_{q}-\omega L i_{d}-\frac{S_{q}}{2} V_{d c}+e_{q} .
\end{aligned}
$$

With (5) plus (6), we can obtain

$$
C \frac{d V_{d c}}{d t}=\frac{3}{2}\left(S_{d} i_{d}+S_{q} i_{q}\right)-2 i_{l} .
$$

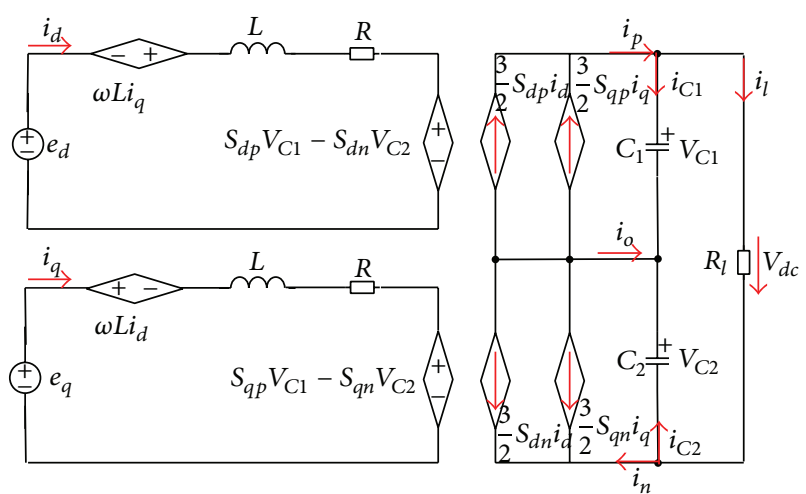

FIGURE 2: Equivalent circuit of VIENNA rectifier in $d$ - $q$ coordinates.

\section{Control Goal and Control Strategies}

The main control goal for VIENNA rectifier is to make sure that input current waveform is sinusoid and track the input voltage waveform, the power factor is unity, and DC side output voltage stabilized at the given reference voltage. Equations (8)-(9) show that VIENNA rectifier is a strong decoupling nonlinear system. In order to realize the variables decoupling in $d-q$ axis, ensure that input current is sinusoid and tracks input voltage; the feedback linearization technology is used in the inner current loop. At the same time, sliding mode control based on index reaching law is used in the voltage loop to stabilize the output voltage and provide the reference directive current $i_{d}^{*}$ for inner current loop.

3.1. Inner Current Loop Controller Design Based on Feedback Linearization. The role of inner current loop is making $i_{d}$ and $i_{q}$ keep track of reference directive current $i_{d}^{*}$ and $i_{q}^{*}$, respectively, and realizes system unity power factor operation.

3.1.1. Affine Nonlinear Models of VIENNA Rectifier. Select state variables as

$$
x=\left[\begin{array}{l}
x_{1} \\
x_{2}
\end{array}\right]=\left[\begin{array}{l}
i_{d} \\
i_{q}
\end{array}\right] .
$$

Select input variables as

$$
u=\left[\begin{array}{l}
u_{1} \\
u_{2}
\end{array}\right]=\left[\begin{array}{l}
S_{d} \\
S_{q}
\end{array}\right] .
$$

Select output variables as

$$
\begin{aligned}
& y_{1}=h_{1}[x(t)]=i_{d}, \\
& y_{2}=h_{2}[x(t)]=i_{q} .
\end{aligned}
$$

According to (8), we get the affine nonlinear equation for two-input and two-output system as follows:

$$
\begin{aligned}
\dot{x}=f(x) & +g_{1}(x) u_{1}+g_{2}(x) u_{2}, \\
y_{1} & =h_{1}[x(t)], \\
y_{2} & =h_{2}[x(t)],
\end{aligned}
$$


where

$$
\begin{gathered}
f(x)=\left[\begin{array}{c}
-\frac{R}{L} i_{d}+\omega i_{q}+\frac{1}{L} e_{d} \\
-\frac{R}{L} i_{q}-\omega i_{d}+\frac{1}{L} e_{q}
\end{array}\right], \quad g_{1}(x)=\left[\begin{array}{c}
-\frac{V_{d c}}{2 L} \\
0
\end{array}\right], \\
g_{2}(x)=\left[\begin{array}{c}
0 \\
-\frac{V_{d c}}{2 L}
\end{array}\right] .
\end{gathered}
$$

For the system which is described in (13), it is nonlinear to state variable $X(t)$ while linear to controlled variable $u$.

\subsubsection{Linearization Processing of VIENNA Rectifier}

Lemma 1 (see [22]). Let one assume $B(x)=\left[b_{1}, \ldots, b_{m}\right]$ as a nonsingular matrix and define the following sets:

$$
\begin{gathered}
G_{0}(x)=\left\{b_{1}, \ldots, b_{m}\right\}, \\
G_{1}(x)=\left\{b_{1}, \ldots, b_{m}, a d_{f} b_{1}, \ldots, a d_{f} b_{m}\right\}, \\
\vdots \\
G_{i}(x)=\left\{a d_{f}^{k}: 0 \leq k \leq i, 1 \leq k \leq m\right\}, \quad i=0,1, \ldots, n-1 .
\end{gathered}
$$

So, the necessary and sufficient conditions for these linearization solutions above are as follows:

(1) for each $i=0,1, \ldots, n-1$, the distribution $G_{i}(x)$ has constant dimension near $x$;

(2) for each $i=0,1, \ldots, n-1$, the distribution $G_{i}(x)$ is involution;

(3) the dimension of $G_{n-i}(x)$ is $n$.

According to the requirements of exact linearization for nonlinear system, verify the two-input and two-output affine nonlinear system described in (13) as follows:

$$
\begin{gathered}
a d_{f} g_{1}(x)=\frac{\partial g_{1}(x)}{\partial x} f(x)-\frac{\partial f(x)}{\partial x} g_{1}(x)=\left[\begin{array}{c}
0 \\
\frac{-\omega V_{d c}}{2 L}
\end{array}\right], \\
a d_{f} g_{2}(x)=\frac{\partial g_{2}(x)}{\partial x} f(x)-\frac{\partial f(x)}{\partial x} g_{2}(x)=\left[\begin{array}{c}
\frac{\omega V_{d c}}{2 L} \\
0
\end{array}\right] .
\end{gathered}
$$

From (16), we can obtain this conclusion: the total relative degree $r=1+1=2$, which just right equals the system's dimension $n$. Meanwhile, when $n=2$, the vector $D=\left[\begin{array}{llll}g_{1}(X) & g_{2}(X) & a d_{f} g_{1}(X) & a d_{f} g_{2}(X)\end{array}\right]$ is involution. Hence, it meets the requirements of linearization.

Taking Lie derivative for (13), we can obtain

$$
\begin{aligned}
& \dot{x}_{1}=L_{f} h_{1}(x)+L_{g_{1}} h_{1}(x) u_{1}+L_{g_{2}} h_{1}(x) u_{2}, \\
& \dot{x}_{2}=L_{f} h_{2}(x)+L_{g_{1}} h_{2}(x) u_{1}+L_{g_{2}} h_{2}(x) u_{2},
\end{aligned}
$$

where

$$
\begin{gathered}
L_{g_{1}} h_{1}(x)=L_{g_{2}} h_{2}(x)=-\frac{V_{d c}}{2 L}, \\
L_{g 2} h_{1}(x)=L_{g 1} h_{2}(x)=0, \\
L_{f} h_{1}(x)=-\frac{R}{L} i_{d}+\omega i_{q}+\frac{e_{d}}{L}, \\
L_{f} h_{2}(x)=-\frac{R}{L} i_{q}-\omega i_{d}+\frac{e_{q}}{L} .
\end{gathered}
$$

3.1.3. Coordinate Transformation and the Control Law. Select output vector as

$$
y=\left[\begin{array}{l}
y_{1} \\
y_{2}
\end{array}\right]=\left[\begin{array}{l}
i_{d} \\
i_{q}
\end{array}\right] .
$$

According to the definition of relative degree [22], the derivative of two input/output system output functions is

$$
\left[\begin{array}{l}
\dot{y}_{1} \\
\dot{y}_{2}
\end{array}\right]=\left[\begin{array}{l}
L_{f} h_{1} \\
L_{f} h_{2}
\end{array}\right]+A(x)\left[\begin{array}{l}
u_{1} \\
u_{2}
\end{array}\right]=\alpha(x)+A(x) u,
$$

where

$$
A(x)=\left[\begin{array}{cc}
-\frac{V_{d c}}{2 L} & 0 \\
0 & -\frac{V_{d c}}{2 L}
\end{array}\right] .
$$

In the meanwhile, since the matrix $A(x)$ is invertible, the state feedback control law is given by

$$
\left[\begin{array}{l}
u_{1} \\
u_{2}
\end{array}\right]=-A^{-1}(x)\left(\left[\begin{array}{l}
L_{f} h_{1} \\
L_{f} h_{2}
\end{array}\right]+\left[\begin{array}{l}
v_{1} \\
v_{2}
\end{array}\right]\right) .
$$

In order to track the desired value, a new control law is given by [14]

$$
\begin{aligned}
& v_{1}=-k_{10}\left(y_{1}^{*}-y_{1}\right) \\
& v_{2}=-k_{20}\left(y_{2}^{*}-y_{2}\right) .
\end{aligned}
$$

From (20), (22), and (23), the new state feedback control law of the original nonlinear inner current loop is obtained:

$$
\left[\begin{array}{l}
u_{d} \\
u_{q}
\end{array}\right]=-\frac{2}{V_{d c}}\left(\left[\begin{array}{l}
R i_{d}-\omega i_{q}-e_{d} \\
\omega i_{d}+R i_{q}-e_{q}
\end{array}\right]+\left[\begin{array}{l}
-k_{10}\left(y_{1}^{*}-y_{1}\right) \\
-k_{20}\left(y_{2}^{*}-y_{2}\right)
\end{array}\right]\right) \text {. }
$$

So far, the original nonlinear system is linearization. Meanwhile, the control for inner current loop can be achieved by setting feedback coefficients $k_{10}$ and $k_{20}$.

3.1.4. Analysis of System Dynamic Stability. Because of the relative degree of (8) being 1 and according to the literature [14], we can get the error dynamic closed-loop system as follows:

$$
\begin{gathered}
\dot{e}_{1}+k_{10} e_{1}=0, \\
\dot{e}_{2}+k_{20} e_{2}=0, \\
\dot{z}=a\left(z, e+y^{*}, \xi\right),
\end{gathered}
$$

where $\xi=\left[\begin{array}{ll}\dot{y}_{1} & \dot{y}_{2}\end{array}\right]^{T}, e_{i}=y_{i}^{*}-y_{i}(i=1,2)$. 
Lemma 2. For internal dynamic formula (27), when tracking errore vanishes, that is

$$
\dot{z}=a\left(z, y^{*}, 0\right)
$$

it is called the zero dynamics [14]. And if a nonlinear system's zero dynamics is asymptotically stable, it is said to be minimum phase.

Because the power supply is three-phase symmetrical voltage and the rectifier is operated with unity power factor and considered in the steady state, we have $e_{d}=E_{m}, V_{d c}=$ $V_{d c}^{*}, i_{d}=I_{d}^{*}$ and $i_{q}=0$. Therefore, (8) and (9) can be simplified as follows:

$$
\begin{gathered}
R I_{d}^{*}+\frac{S_{d}^{\prime} V_{d c}^{*}}{2}=E_{m}, \\
\omega L I_{d}^{*}+\frac{S_{q}^{\prime} V_{d c}^{*}}{2}=0, \\
\frac{3}{2} S_{d}^{\prime} I_{d}^{*}=2 I_{l},
\end{gathered}
$$

where $S_{d}^{\prime}, S_{q}^{\prime}, I_{d}^{*}$, and $I_{l}$ represent the steady-state values of the switching functions $S_{d}$ and $S_{q}, d$-axis reference current $i_{d}^{*}$, and output load current $i_{l}$, respectively.

By contrast, we find that (29) are the same as (21)-(23) in [14], so the dynamic analysis of VIENNA rectifier can learn from the literature [14].

Transform the original nonlinear system (13) into the linear form of (25)-(27) with $z=x_{3}=V_{d c}$. The internal dynamics (27) becomes

$$
\begin{aligned}
\dot{x}_{3}= & -\frac{3 L}{2 C} \frac{i_{d}}{V_{d c}}\left[k_{10}\left(I_{d}^{*}-i_{d}\right)+\frac{R}{L} i_{d}+\omega i_{q}-\frac{E_{m}}{L}\right] \\
& -\frac{3 L}{2 C} \frac{i_{q}}{V_{d c}}\left[-k_{20} i_{q}+\frac{R}{L} i_{q}-\omega i_{d}\right]-\frac{1}{C} i_{l} .
\end{aligned}
$$

According to the energy balance and because of the tracking error vector $e$ approaching zero, that is, $i_{d} \rightarrow I_{d}^{*}$ and $i_{q} \rightarrow 0$, we can get the following zero dynamics equation:

$$
\dot{x}_{3}=\frac{1}{R_{l} C x_{3}}\left(V_{d c}^{* 2}-x_{3}^{2}\right) \text {. }
$$

From (31), we can know the following. For a positive initial $d c$ side output voltage, the steady-state value of $x_{3}$ will eventually equal the desired value of $V_{d c}^{*}$. So, when using cascaded current mode, the control system is a minimum phase system, and the dynamic is stability. Therefore, we can design a superior performance control system.

\subsection{Voltage Loop Controller Design Based on Sliding Mode} Control. The role of voltage loop controller is to guarantee output voltage $V_{d c}$ tracking the given reference voltage $V_{d c}^{*}$ and stable. In the meantime, voltage loop controller provides $d$-axis reference current $i_{d}^{*}$ for the current loop.

For (24), $i_{d}$ and $i_{q}$ can be acquired by taking Park's transformation to input currents $i_{a}, i_{b}$, and $i_{c}$. For dual closed loop control system which adopts inner current loop and outer voltage loop, $i_{d}^{*}$ is always provided by the outer loop. For three-level PWM rectifier, PI algorithm [23], fractional control algorithm [24], and sliding mode control algorithm [25] are used in the outer voltage loop. Since inner current loop uses feedback linearization control, it brings a shortcoming for this control system; that is, the control system is overreliance on accurate mathematical model. In order to compensate this shortcoming, sliding mode control algorithm is used in the outer voltage loop. One of the biggest advantages for sliding mode control is insensitive to the change of system parameters and having less demand for control system model. In order to avoid chattering, improve the approaching performance, index reaching law is introduced based on sliding mode control which is described in [25].

Let us assume the error between dc output voltage and the given reference voltage as follows:

$$
V_{e}=V_{d c}^{*}-V_{d c} .
$$

Based on the principle of sliding mode control [26, 27], the sliding surfaces can be defined as

$$
S_{d c}=V_{e}+k_{3} \int_{0}^{t} V_{e} d t, \quad k_{3}>0
$$

When $S_{d c}=0$, the system runs in sliding mode surface. Take a derivate on both sides of (33), and because $V_{d c}^{*}$ is constant, yield

$$
\dot{S}_{d c}=-\frac{d V_{d c}}{d t}+k_{3} V_{e} .
$$

According to (9), (34) can be rewritten as

$$
\dot{S}_{d c}=-\frac{3}{2 C}\left(S_{d} i_{d}+S_{q} i_{q}\right)+\frac{2}{C} i_{l}+k_{3} V_{e}
$$

In order to guarantee the system having a good quality in the transition process, especially improving the quality of arrival stage, and eliminating the chattering phenomenon, index reaching law is applied [26]:

$$
\dot{S}=-\varepsilon \operatorname{sgn} S-\lambda S \quad \varepsilon>0, \lambda>0 .
$$

According to the literature [26], yield

$$
\begin{aligned}
& S(t)=\frac{\varepsilon}{\lambda}+\left(S(0)-\frac{\varepsilon}{\lambda}\right) e^{-k t}, \quad S>0 \\
& S(t)=\frac{-\varepsilon}{\lambda}+\left(S(0)+\frac{\varepsilon}{\lambda}\right) e^{-k t}, \quad S<0 .
\end{aligned}
$$

From (37), we can obtain

$$
t^{*}=\frac{1}{\lambda}\left(\ln \left(S+\frac{\varepsilon}{\lambda}\right)-\ln \frac{\varepsilon}{\lambda}\right) .
$$

From (38), it shows that reducing $\varepsilon$ and increasing $\lambda$ can accelerate the approaching process. 
From (35) and (36), we can obtain

$$
\lambda S_{d c}+\varepsilon \operatorname{sgn}\left(S_{d c}\right)-\frac{3}{2 C}\left(S_{d} i_{d}+S_{q} i_{q}\right)+\frac{2}{C} i_{l}+k_{3} V_{e}=0 .
$$

Further, (39) can be transformed as follows:

$$
\left[\lambda S_{d c}+\varepsilon \operatorname{sgn}\left(S_{d c}\right)-\frac{3}{2 C} S_{q} i_{q}+\frac{2}{C} i_{l}+k_{3} V_{e}\right] \cdot \frac{2 C}{3 S_{d}}-i_{d}=0 .
$$

According to the above assumption, power grid is symmetrical three-phase voltage. When the system is in steady state, yield $i_{q}=0, d i_{q} / d t=0, e_{d}=\sqrt{3} U_{\mathrm{RMS}}, e_{q}=0, V_{d c}=V_{d c}^{*}$. At the same time, the processing speed of inner loop is faster than the outer loop. Thus, $i_{d}$ can be seen as constant; yield $d i_{d} / d t=0$. From (8), the following approximation algorithm can be obtained:

$$
\begin{gathered}
S_{d} \approx \frac{2\left(e_{d}-R i_{d}\right)}{V_{d c}}, \\
S_{q} \approx-\frac{2 \omega L i_{q}}{V_{d c}} .
\end{gathered}
$$

From (40) and (41), we can obtain

$$
\begin{aligned}
i_{d}= & \frac{C V_{d c}}{3\left(\sqrt{3} U_{\mathrm{RMS}}-R i_{d}\right)} \\
& \cdot\left[\lambda\left(V_{e}+k_{3} \int_{0}^{t} V_{e} d t\right)+\varepsilon \operatorname{sgn}\left(V_{e}+k_{3} \int_{0}^{t} V_{e} d t\right)\right. \\
& \left.+\frac{2 i_{l}}{C}+k_{3} V_{e}\right] .
\end{aligned}
$$

When the system is in steady state, $i_{d}=i_{d}^{*}$. So, (42) is rewritten as

$$
\begin{aligned}
i_{d}^{*}= & \frac{C V_{d c}}{3\left(\sqrt{3} U_{\mathrm{RMS}}-R i_{d}\right)} \\
& \cdot\left[\lambda\left(V_{e}+k_{3} \int_{0}^{t} V_{e} d t\right)+\varepsilon \operatorname{sgn}\left(V_{e}+k_{3} \int_{0}^{t} V_{e} d t\right)\right. \\
& \left.+\frac{2 i_{l}}{C}+k_{3} V_{e}\right] .
\end{aligned}
$$

As a result, the output of outer voltage loop just is the current instructions $i_{d}^{*}$ for the inner loop, which is relevant to the output voltage, output current, valid value of phase voltage, $d$-axis current $i_{d}$, and so on. Besides, $i_{d}^{*}$ is irrelevant to the switching function variables.

3.3. Control System Block Diagram. According to the above analysis, we can get the control system block diagram as shown in Figure 3.

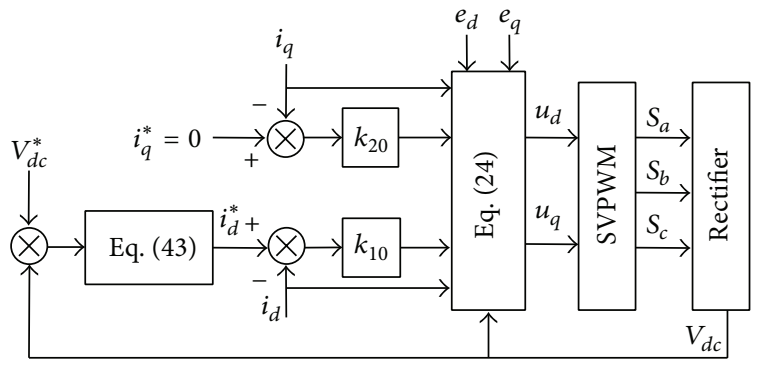

Figure 3: Control system block diagram.

TABLE 1: Simulation parameters.

\begin{tabular}{lc}
\hline Input phase voltage & $e_{(a, b, c)}=110 \mathrm{~V}$ \\
Output reference voltage & $V_{d c}^{*}=400 \mathrm{~V}$ \\
Boost inductance & $L=2.8 \mathrm{mH}$ \\
Line equivalent impedance & $R=0.1 \Omega$ \\
Output filtering capacitor & $C_{1}=C_{2}=680 \mu \mathrm{F}$ \\
Nominal load resistance & $R_{l}=100 \Omega$ \\
Power rating & $P=1.6 \mathrm{KW}$ \\
Switching frequency & $f=10 \mathrm{KHz}$ \\
\hline
\end{tabular}

\section{Simulation Results}

In order to verify the correctness and superiority of the proposed control method, the simulation model is built in the simulation platform of Matlab/Simulink. The main simulation parameters are given in Table 1. SVPWM algorithm based on two-level space vector is used in modulation methods of VIENNA rectifier. Small positive vector is set as the first vector, by judging the direction of phase load current which is connected to the output neutral point and adjusting relative action time according to the imbalance between small positive and negative vectors. Voltage regulating factor $r(0<$ $r<1)$ is introduced. The adjustment to vector action time is done so as to realize the midpoint potential balance control.

4.1. System Startup Responses. When the system is started, DC side output voltage rapidly rises from $0 \mathrm{~V}$ and stabilizes at reference voltage $V_{d c}^{*}$ approximately at $0.0035 \mathrm{~s}$, the response waveforms of output voltage are shown in Figure 4 . At the same time, it shows that the system has a rapid response, without overshoot and static error. Also, it verifies that using sliding mode control method could force the system running path moving fast to sliding surfaces, thereby accelerating the convergence process of the system.

4.2. System Steady-State Characteristics. When VIENNA rectifier is operating in steady state, input current waveform tracks input voltage waveform very well and shows sinusoid, as shown in Figure 5(a); the active current $i_{d}$ can well track reference current $i_{d}^{*}$ given by outer voltage loop, as shown in Figure 5(b); the reactive current $i_{q}$ is 0 , which means the rectifier operates with unit power factor, as shown in Figure 5(c). The simulation waveforms indicate that the VIENNA rectifier reaches predetermined target. 


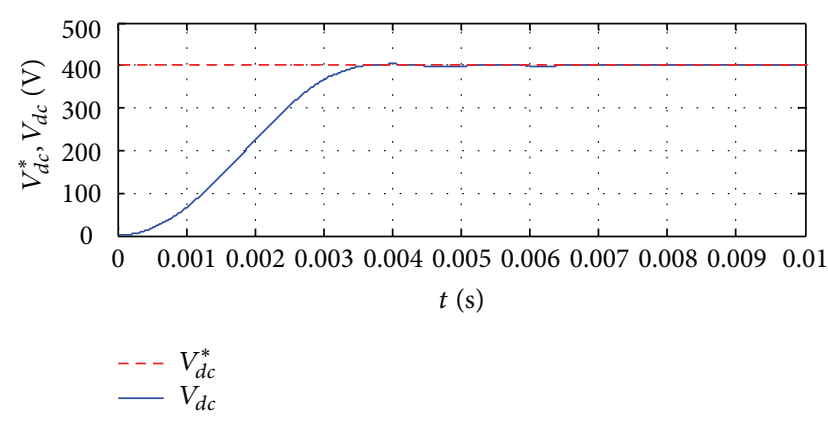

FIGURE 4: Response waveforms of output voltage when system starts up.

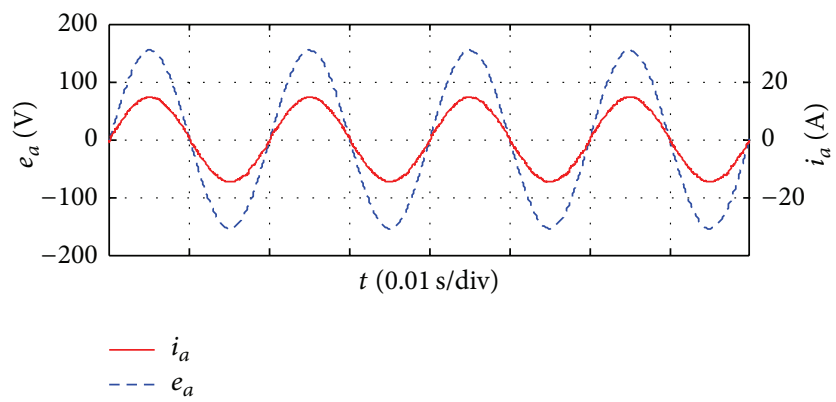

(a)

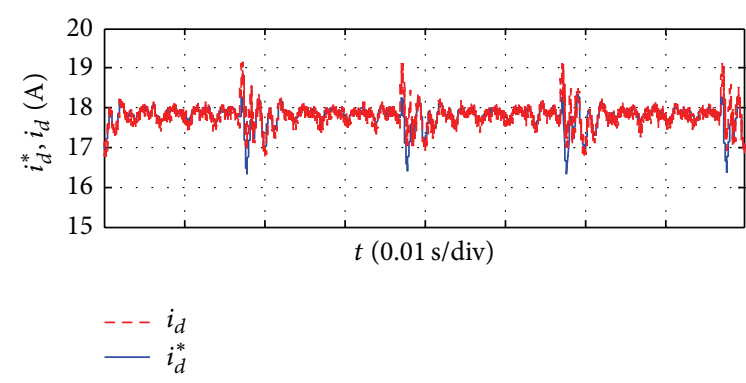

(b)

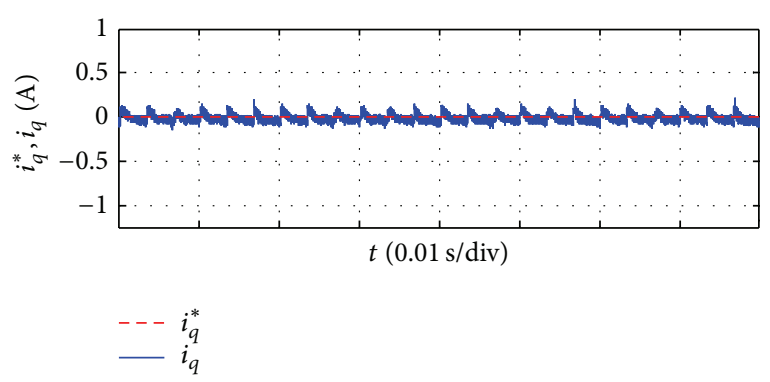

(c)

FIGURE 5: Steady-state simulation waveforms.

4.3. Transient Responses to Step Changes in Load. When load suddenly changes, the simulation waveforms are shown in Figure 6. The value of load resistance $R_{l}$ is changed from $100 \Omega$ to $200 \Omega$ at 0.05 s. As shown in Figure 6(a), DC side output voltage rises to about $6 \mathrm{~V}$ instantaneously and then reverts to a stable value $(400 \mathrm{~V})$ after $0.001 \mathrm{~s}$. Figure 6(b) shows that input current also suddenly changes. However,

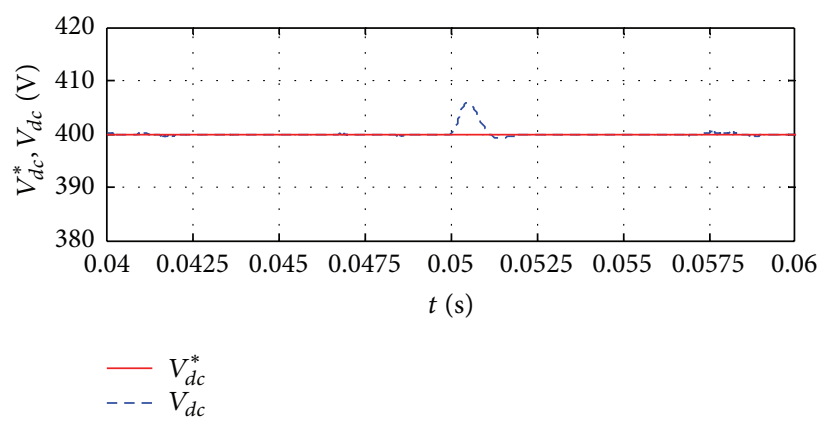

(a)

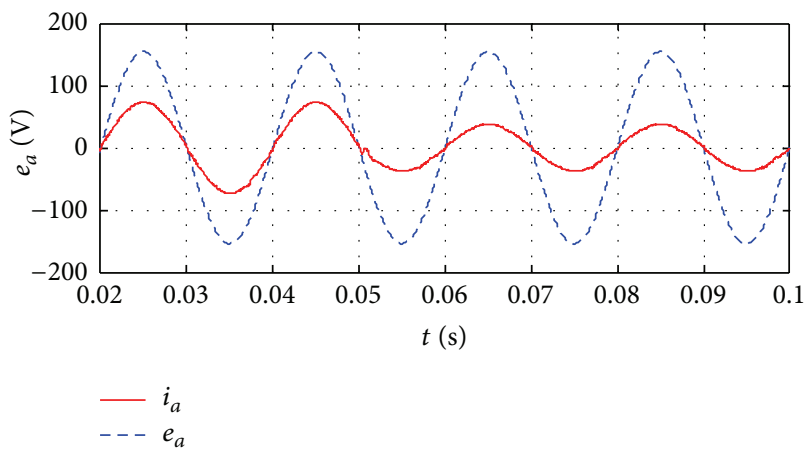

(b)

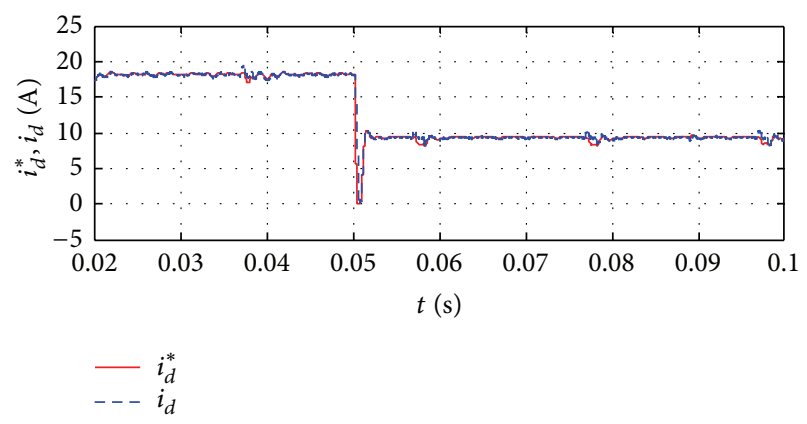

(c)

FIGURE 6: Transient responses to step changes in load.

input current waveform can correctly track the input voltage waveform and maintain sinusoid. Figure 6(c) shows that active current $i_{d}$ can correctly track the given active current reference $i_{d}^{*}$. At the same time, the system response time is short. In a word, it shows significant anti-interference capability to external disturbance by using the proposed strategy.

4.4. Transient Responses to Step Changes in the Given Output Reference Voltage. Assuming output voltage value instantaneously declines to $350 \mathrm{~V}$ at $0.06 \mathrm{~s}$, the simulation waveforms are shown in Figure 7. From Figure 7(a), output voltage begins to decrease at $0.06 \mathrm{~s}$ and stabilized at $350 \mathrm{~V}$ after $0.003 \mathrm{~s}$. From Figure 7(b), $a$-phase input current value is 0 at $0.06 \mathrm{~s}$ and lasts about $0.003 \mathrm{~s}$. Since then, it starts to increase rapidly and tracks input voltage and remains sinusoid. 

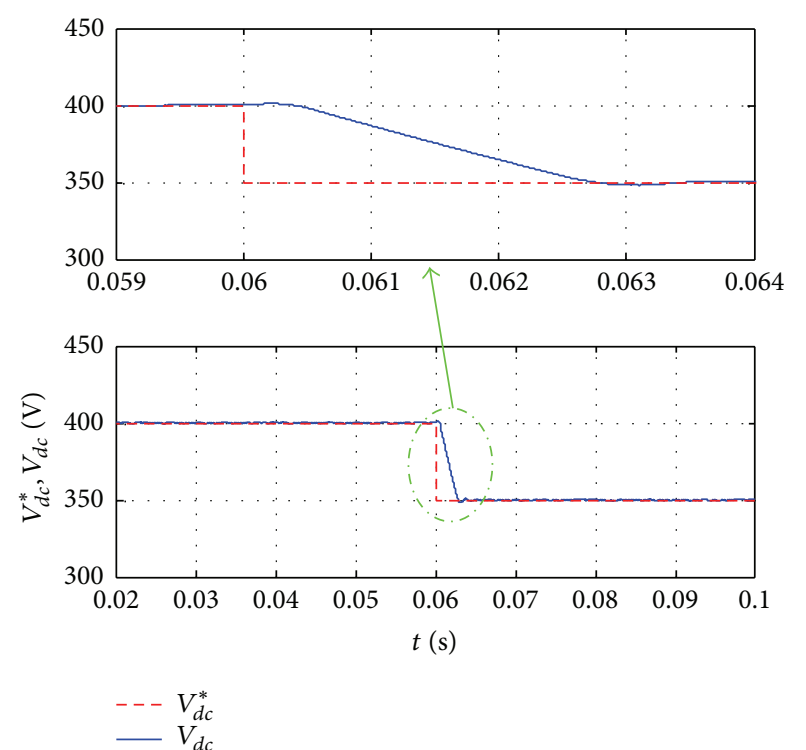

(a)

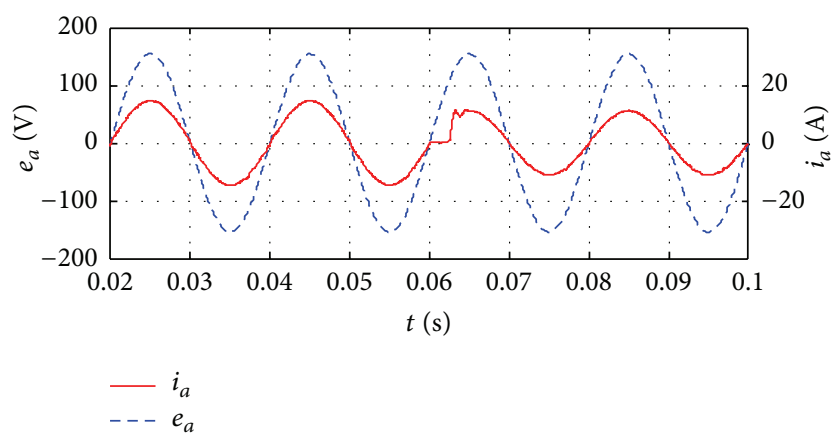

(b)

FIGURE 7: Transient responses to step changes in the given output reference voltage.

\section{Conclusions}

In this paper, a dual closed loop control method, that is, outer voltage loop based on sliding mode control and inner current loop based on feedback linearization, is proposed. Simulation results show that the proposed control strategy has a good control effect. The main contributions of this paper are as follows.

(i) It presents feedback linearization control strategy for VIENNA rectifier inner current loop such that it solves the linearization problems and realizes $d$ - $q$ axis variable decoupling.

(ii) It presents sliding mode control strategy for VIENNA rectifier outer voltage loop and introduces the index reaching law such that it solves stability of output voltage, system startup response, and dynamic characteristics.

(iii) The combination control strategy overcomes the disadvantage that the system is overreliance on the accurate mathematical models by using feedback linearization control strategy. Meanwhile, the proposed control strategy greatly improves the robustness of the system.

\section{Conflict of Interests}

The authors declare that there is no conflict of interests regarding the publication of this paper.

\section{Acknowledgments}

This work was partially supported by the National Natural Science Foundation of China (512277034) and the Scientific Research Foundation of GuangXi University (XJZ120282).

\section{References}

[1] M. Narimani and G. Moschopoulos, "A three-level integrated ac-dc converter," IEEE Transactions on Power Electronics, vol. 29, no. 4, pp. 1813-1820, 2014.

[2] H.-Y. Jin, Y.-P. Zou, L. Lin et al., "Research on the technology of the neutral-point voltage balance and dual-loop control scheme for three-level pwm rectifier," Proceedings of the Chinese Society of Electrical Engineering, vol. 26, no. 20, pp. 64-68, 2006.

[3] J. W. Kolar and F. C. Zach, "A novel three-phase utility interface minimizing line current harmonics of high-power telecommunications rectifier modules," in Proceedings of the 16th International Telecommunications Energy Conference, pp. 367-374, Vancouver, Canada, November 1994.

[4] R. X. Lai, F. Wang, P. Q. Ning et al., "A high-power-density converter," IEEE Industrial Electronics Magazine, vol. 4, no. 4, pp. 4-12, 2010.

[5] R. Amirhossein, M. Mustafa, D. S. Mohamad, and Y. Ali, "Vienna-rectifier-based direct torque control of PMSG for wind energy application," IEEE Transactions on Industrial Electronics, vol. 60, no. 7, pp. 2919-2929, 2013.

[6] L. Hang, M. Zhang, L. M. Tolbert, and Z. Lu, "Digitized feedforward compensation method for high-power-density threephase Vienna PFC converter," IEEE Transactions on Industrial Electronics, vol. 60, no. 4, pp. 1512-1519, 2013.

[7] B. Kedjar, H. Y. Kanaan, and K. Al-Haddad, "Vienna rectifier with power quality added function," IEEE Transactions on Industrial Electronics, vol. 61, no. 8, pp. 3847-3856, 2014.

[8] N. Bel Hadj-Youssef, K. Al-Haddad, H. Y. Kanaan, and F. Fnaiech, "Small-signal perturbation technique used for DSPbased identification of a three-phase three-level boost-type Vienna rectifier," IET Electric Power Applications, vol. 1, no. 2, pp. 199-208, 2007.

[9] N. B. H. Youssef, K. Al-Haddad, and H. Y. Kanaan, "Large-signal modeling and steady-state analysis of a $1.5-\mathrm{kW}$ three-phase/ switch/level (Vienna) rectifier with experimental validation," IEEE Transactions on Industrial Electronics, vol. 55, no. 3, pp. 1213-1224, 2008.

[10] R. Ansari, M. R. Feyzi, K. Akbari Hamed, N. Sadati, Y. Yasaei, and S. Ouni, "Input-output linearisation of a fourth-order input-affine system describing the evolution of a three-phase/ switch/level (Vienna) rectifier," IET Power Electronics, vol. 4, no. 8, pp. 867-883, 2011.

[11] A. I. Maswood, E. Al-Ammar, and F. Liu, "Average and hysteresis current-controlled three-phase three-level unity power factor 
rectifier operation and performance," IET Power Electronics, vol. 4, no. 7, pp. 752-758, 2011.

[12] W. Song, J. Huang, Y. Zhong, and L. Wang, "A hysteresis current control method with neutral point potential balancing control for Vienna rectifier," Power System Technology, vol. 37, no. 7, pp. 1909-1914, 2013.

[13] L. He and X. Chen, "Optimized PI current controller of three level unidirectional PWM rectifier under variable inductance," Transactions of China Electrotechnical Society, vol. 26, no. 7, pp. 203-209, 2011.

[14] T.-S. Lee, "Input-output linearization and zero-dynamics control of three-phase AC/DC voltage-source converters," IEEE Transactions on Power Electronics, vol. 18, no. 1, pp. 11-22, 2003.

[15] W. H. Deng, B. Zhang, and D. Y. Qiu, "The research of decoupled state variable feedback linearization control method of three-phase voltage source PWM rectifier," Proceedings of the CSEE, vol. 25, no. 7, pp. 97-103, 2005.

[16] P. Yang, X. H. Zhang, and H. J. Chen, "Study of model quasi-linearization of three-phase voltage-type PWM rectifiers," Transactions of China Electrotechnical Society, vol. 22, no. 8, pp. 28-35, 2007.

[17] Y. J. Qian and B. T. Gao, "Passivity-based sliding mode nonlinear control of PWM rectifier," Information and Control, vol. 41, no. 2, pp. 238-243, 2012.

[18] Z. Zhang, Y.-X. Xie, J.-Y. Le, L. Chen, and H.-Y. Chen, "Feedback linearization and sliding-mode control of three-phase voltage source PWM rectifier," Journal of South China University of Technology (Natural Science), vol. 37, no. 11, pp. 71-75, 2009.

[19] Z. J. Ding, B. L. Liu, and W. Ni, "Design of improved variable structure control for PWM rectifier," Electric Power Automation Equipment, vol. 32, no. 1, pp. 76-83, 2012.

[20] Y.-Q. Tang, K.-Y. Zhao, and C. Wang, "Three-phase PWM rectifier based on sliding-mode variable structure control," Electric Power Automation Equipment, vol. 26, no. 5, pp. 39-41, 2006.

[21] R. Burgos, R. Lai, Y. Pei, F. Wang, D. Boroyevich, and J. Pou, "Space vector modulator for Vienna-type rectifiers based on the equivalence between two- and three-level converters: a carrierbased implementation," IEEE Transactions on Power Electronics, vol. 23, no. 4, pp. 1888-1898, 2008.

[22] Y. M. Hu, Variable Structure Control Theory and Applications, Science Press, Beijing, China, 2003.

[23] X.-G. Guo, X.-M. Jin, T.-Y. Ma, and Y.-B. Tong, "Constant frequency control for three-phase voltage PWM rectifier under unbalanced grid voltage conditions based on sliding mode control," Power System Protection and Control, vol. 41, no. 10, pp. 126-133, 2013.

[24] L. Lin, Y. P. Zou, H. Q. Zhong et al., "Study of control system of diode-clamped three-level inverter," Proceedings of the CSEE, vol. 25, no. 15, pp. 33-39, 2005.

[25] J. Zhou, X. Lu, G. Huang, Y. P. Zhou, and S. L. Zhou, "A hybrid control strategy for VIENNA rectifier," International Journal of Applied Mathematics and Statistics, vol. 50, no. 20, pp. 583-592, 2013.

[26] Z. M. Chen, Z. Y. Wang, and J. G. Zhang, Sliding Mode Variable Structure Control Theory and Applications, Electronic Industry Press, Beijing, China, 2012.

[27] S. Chen, C. Kuo, C. Lin, C. Hsu, and C. Tsui, "Applications of fuzzy sliding mode control for a gyroscope system," Abstract and Applied Analysis, vol. 2013, Article ID 931285, 8 pages, 2013. 


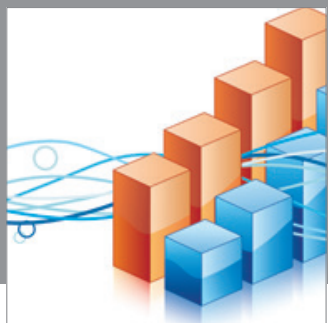

Advances in

Operations Research

mansans

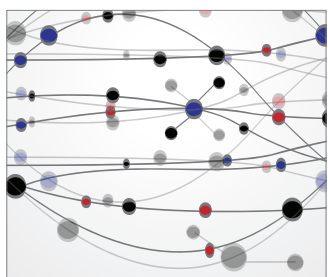

The Scientific World Journal
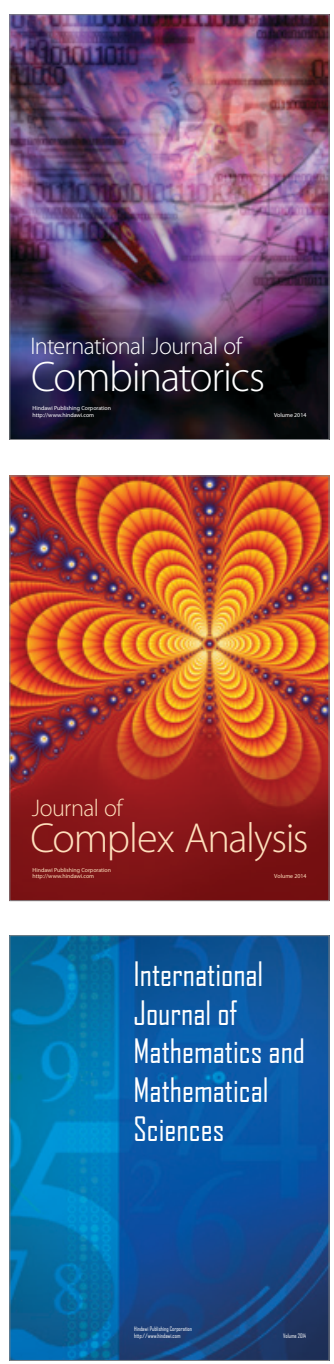
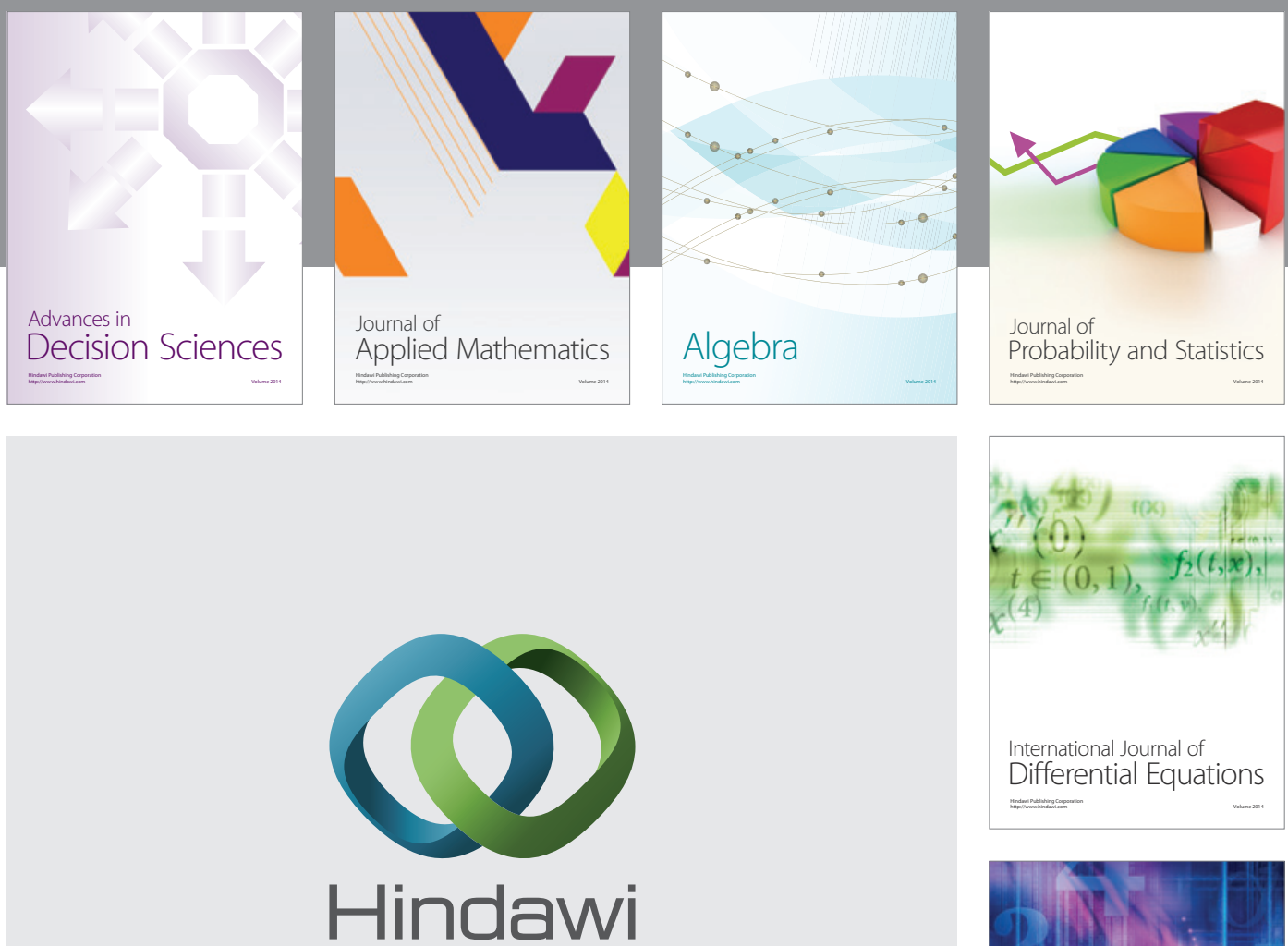

Submit your manuscripts at http://www.hindawi.com
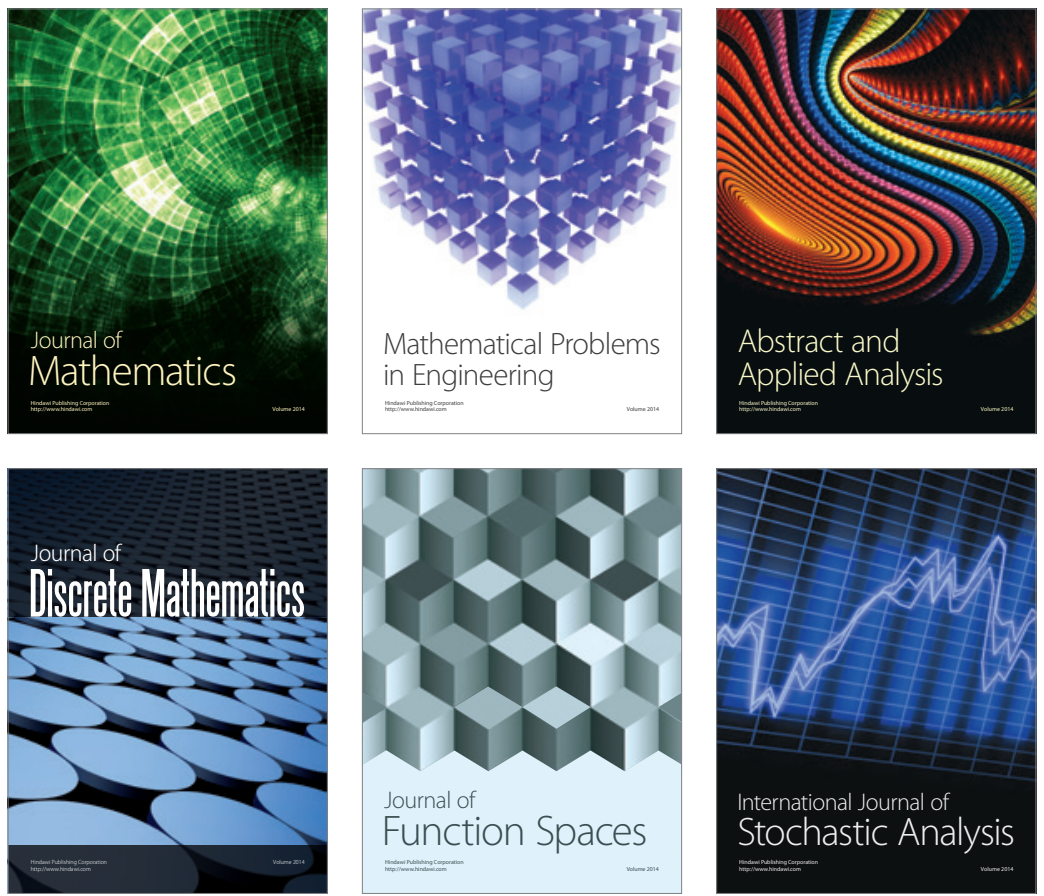

Journal of

Function Spaces

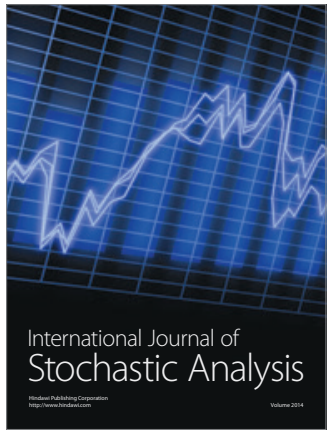

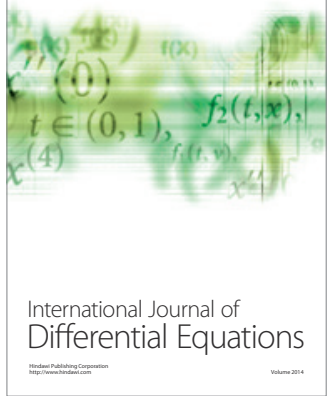
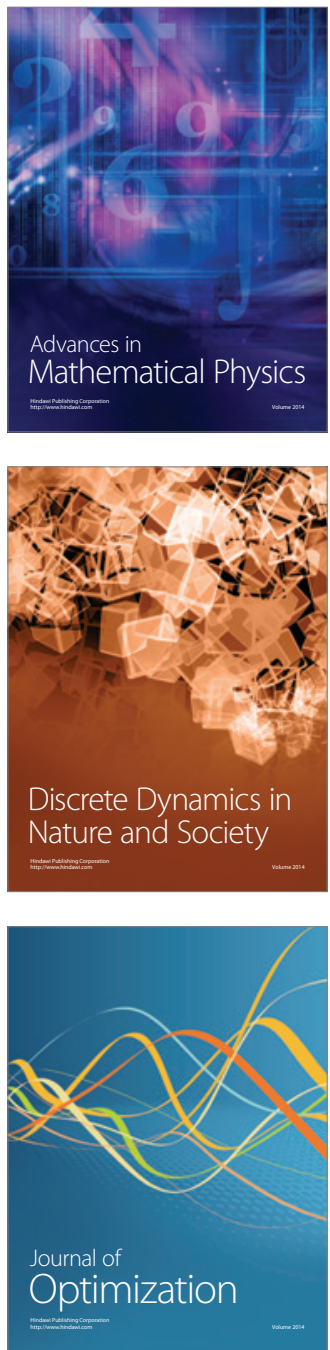